\title{
CT Manifestation of Abscess Occupying the Infratemporal Fossa and Temporoparietal Region in a 73-Year-Old Male- Case Report
}

\author{
Ewa Zawiślak* and Rafał Nowak \\ Department of Maxillofacial Surgery, Silesian Piast Medical University, Poland
}

*Corresponding author: Ewa Zawiślak, Department of Maxillofacial Surgery, Silesian Piast Medical University, Borowska 213, Wrocław 50-556, Poland

\begin{abstract}
Commonly available dental care and a widespread use of antibiotics in an outpatient setting have not eliminated odontogenic infections which may require inpatient admission as potentially life-threatening conditions. The spread of infection to the deep fascia of the head and neck may lead to severe and life-threatening complications, such as airway obstruction, mediastinitis, sepsis and septic shock, endocarditis or intracranial abscess formation. Clinical presentation of deep fasciitis of the head and neck may not correspond to the systemic deterioration in the same patient. Therefore, contrast-enhanced computed tomography should be a standard diagnostic imaging in such cases, as it enables accurate location of inflammation, whereas contrast enhancement enables differentiation between soft tissue inflammation and fluid collections based on their density relative to the one of air. It substantially aides the diagnosis, where the history and clinical presentation are inconclusive. The aim of the paper is to discuss the diagnostic management, presentation and spread of odontogenic infections of the head and neck by presenting the rare case of abscess occupying the left infratemporal fossa and temporoparietal region in a 73-year-old male.
\end{abstract}

Keywords: Craniofacial Ct; Odontogenic abscess; Odontogenic infection; Temporal fossa abscess; Phlegmon of the face; Surgical treatment

\section{Introduction}

\section{General characteristics of head and neck infections}

The head and neck infections have their distinct characteristics which differ them from the infections affecting other anatomical locations. It is primarily associated with a complex craniofacial and cervical anatomy, the presence of teeth in the oral cavity, the proximity of paranasal sinuses, abundant blood supply and the presence of vital sensory organs (visual, auditory and olfactory senses) [1,2]. Inflammation develops as a bodily defense mechanism against a noxious agent, which can be either a physical or a biological (e.g. pathogens). The bacterial infection develops as the host immune barrier becomes compromised. This is the key mechanism responsible for head and neck inflammation and infection. Pulp necrosis, periapical periodontitis with abscess formation, infected dental cysts as well as infectious complications of partially or completely impacted teeth are the main source of pathogens in head and neck infections $[3,4]$. Necrotised pulp of mandibular and maxillary molars, premolars and, less often, single root teeth is the most common site of origin [5-7]. Periodontitis is the aetiologic factor in $20-30 \%$ of odontogenic infections [8-10]. The second group of aetiologic factors in head and neck infections are non-odontogenic conditions, including sialadenitis, sinusitis, lymph node abnormalities, and skin infections, such as furunculus (boil). The inflammation can manifest clinically as inflammatory infiltration, abscess and the most severe form of infection, that is, phlegmon of the head and neck. Odontogenic infections are mostly cause by mixed bacterial flora. The most commonly cultured isolates include Streptococcus viridans and Klebsiella pneumoniae $[10,11]$. As the infection progresses, anaerobic bacteria emerge, which is associated with decreased oxyreductive potential and $\mathrm{pH}$ reduction in affected tissues [12-14].

Synthetic penicillin remains the drugs of choice in odontogenic infections of the head and neck, mainly due to its high efficacy, minimum side effects, easy availability and low cost. Second generation cephalosporins, belonging to the class of -lactam antibiotics, are used qually often. The main representative of this drug category is cefuroxime, which has a very broad spectrum, 
good penetration to the bone tissue, which is vital in treatment of odontogenic infections. It is administered parenterally in its leading pharmaceutical form in an inpatient setting. If anaerobic strain involvement is suspected, metronidazole is a treatment of choice [15-17]. The indications for antibiotic therapy include severe systemic symptoms, extensive local inflammation, immunosuppression, systemic comorbidities (diabetes, RA, liver damage) and upper face or mid-face involvement. Empirical, often combined, treatment should be started immediately and adjusted once the susceptibility testing report is available (usually 72 hours). Cultures and antimicrobial susceptibility testing aim at identifying the causal pathogens, their susceptibility to different antibiotic classes and determining the minimum inhibitory concentration (MIC) needed to inhibit the pathogen growth. The MIC is helpful for determining the effective dosage [18].

\section{Infection spread within the head and neck}

Spread of head and neck infections may occur in a contiguous fashion, along planes of least resistance from the supporting structures of the affected tooth to fascial spaces of the head and neck.Having crossed the strongest barrier of cortical bone and periosteum, the infection spreads along the adjacent soft tissues $[18,19]$. The crucial factors which determine the spread of infection include its site of origin (maxilla, mandible), anatomical relationship between the site of origin and muscle insertions/ ligaments, alongside the detailed anatomy of craniofacial and cervical fascial layers, spaces and fossae. The fascial space is referred to as the anatomical fascia-lined space, which contains loose connective tissue and additional structures. The fascia is a compact connective tissue membrane, which covers muscles, muscle groups and ensures structural integrity of the body. Its function is complex with protection and regeneration of tissue it surrounds as the key role. A thorough knowledge of the anatomy is essential to understand the passageway of infection and associated clinical signs and symptoms $[20,21]$.

\section{Case description}

A 73-year old man presented as an emergency at the Department of Maxillofacial Surgery in Wrocław due to moderately increasing oedema of the left temporal region. He had a history of dental extraction of gangreneous roots of tooth 27 two weeks earlier under local anaesthesia, as well as chronic, treated, hypertension. He reported that 3 days following his extraction, the oedema developed "near his left ear", which subsequently enlarged yet remained fairly asymptomatic. He did not present with any systemic symptoms such as fever, chills or malaise. The patient reported that he saw his GP about it twice, who recommended cold compresses and non-steroidal anti-inflammatory drugs (NSAIDs). Due to the problems with dental visit, GP issued a referral to hospital treatment to Maxillofacial Department. Clinically, intraoral examination revealed severe dental caries, roots of teeth $13,23,32$, 42, 46 eligible for extraction and clinically healed dental alveolus of tooth 27 with no signs of inflammation within the left maxilla. An extraoral examination revealed significant head asymmetry. There was a massive oedema stretching from the left subtemporal space, through to the temporal and parietal region (Figures 1a-1c). The oedematous area was medium-soft, fluctuant and slightly tender upon palpation. There was no history of head or craniofacial injury. The patient was verbally responsive and oriented, in a good general condition, with no signs of fever or malaise. He was admitted to the Department of Maxillofacial Surgery as an inpatient for further diagnostic assessments and treatment.

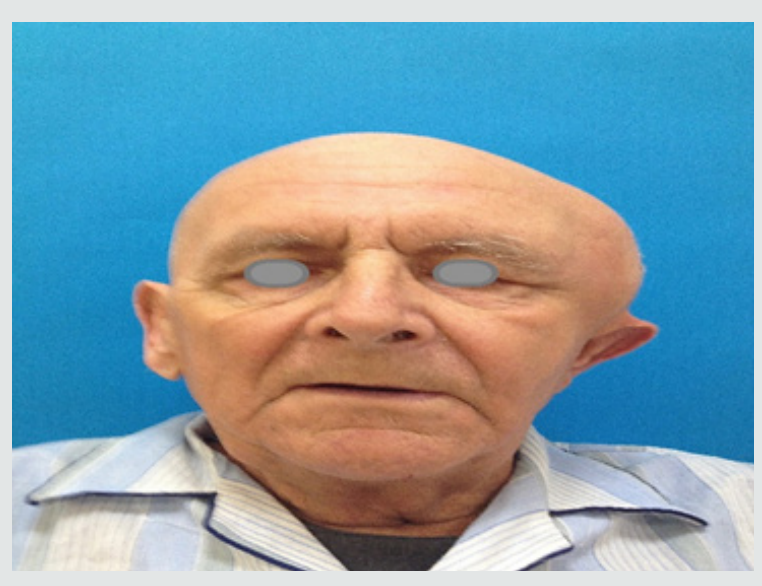

Figure 1a: Patient's head and neck - an "en face" view.

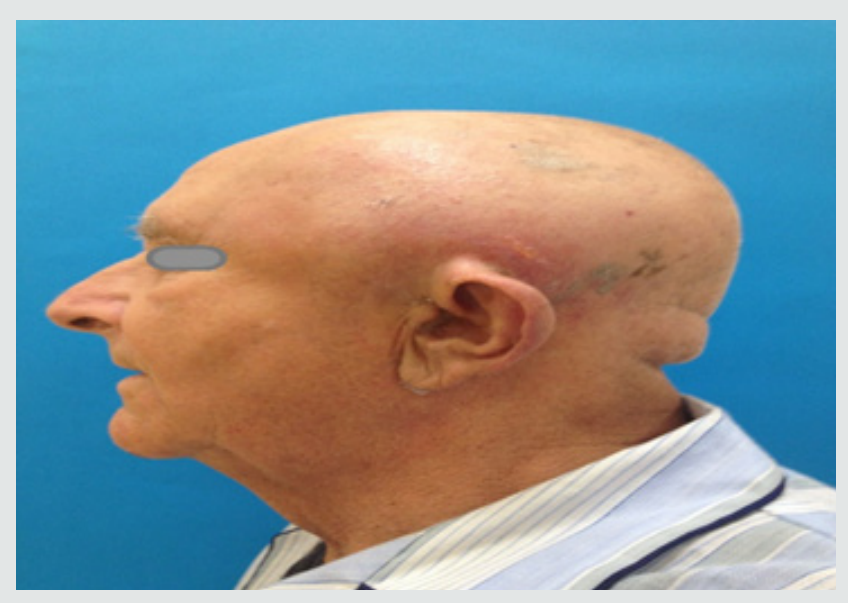

Figure 1b: Patient's head and neck - a left profile view.

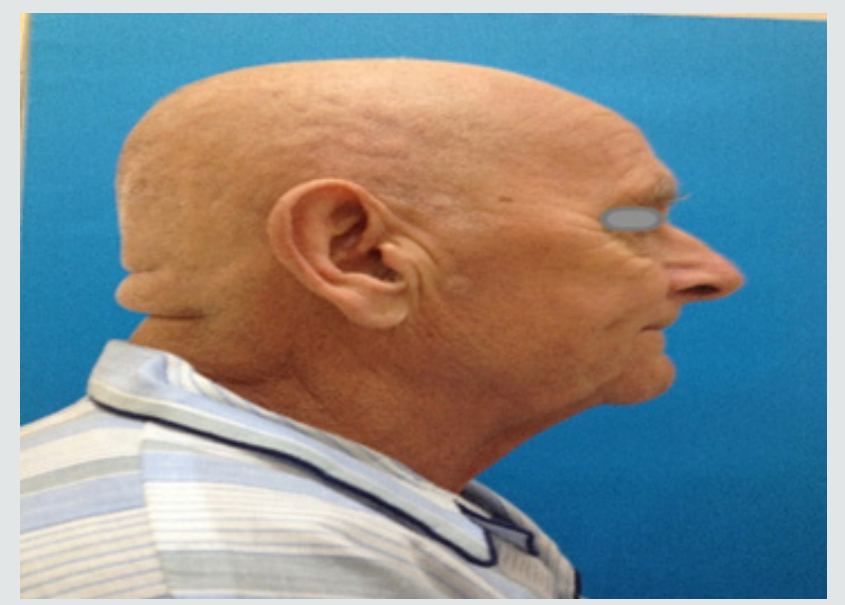

Figure 1c: Patient's head and neck - a right profile view. 
His vital signs at admission were: temperature $36.4 \mathrm{C}$, blood pressure 140/80 and HR 100'. The patient reported using the following medications: trimetazidine MR 35mg (once a day each morning), atorvastatin $20 \mathrm{mg}$ (once a day each morning), ramipril $10 \mathrm{mg}$ (twice a day), aspirin $75 \mathrm{mg}$ (once a day at bedtime), and bisoprolol $5 \mathrm{mg}$ (once a day at bedtime). The WBC count was normal $\left(7.34 * 10^{\wedge} 3 / \mathrm{uL}\right.$, reference range $\left.4-10^{*} 10^{\wedge} 3 / \mathrm{uL}\right)$, but the C-reactive protein level was elevated (CRP $34.40 \mathrm{mg} / \mathrm{L}$, reference range $0-5 \mathrm{mg} / \mathrm{L}$ ). The contrast-enhanced CT of the head was performed immediately. The reported abnormalities included "an irregular area of oedema and inflammatory infiltration within the left masticator space and within the left subtemporal fossa with abscess formation, irregular in outline, sized $2.5 \times 8.0 \mathrm{~cm}$ and small gas collections (...). An extensive abscess and soft tissue phlegmon are present within the cranial integuments, in the left temporoparietal area. The abscess contains gas collections, is $2.7 \mathrm{~cm}$ thick and $12 \mathrm{~cm}$ wide $(\ldots)$.

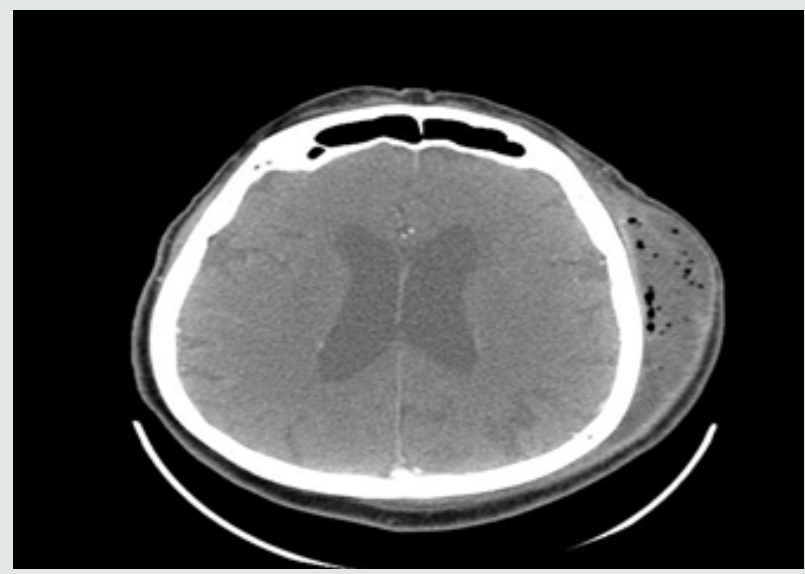

Figure 2: CT image of frontal sinuses plane.

The submandibular lymph nodes and lymph nodes against the carotid vessels on the left are fairly small." The figures below present contrast-enhanced axial computed tomograms of the head and neck (Figures 2-4) and coronal (frontal) image reconstructions (Figures 5-7). In the light of the above findings, empirical intravenous antibiotic therapy was started, including biocefuroxim $1.5 \mathrm{~g}$ every $8 \mathrm{~h}$, metronidazole $500 \mathrm{mg}$ every $8 \mathrm{~h}$, fluid replacement therapy (Ringer fluid $1000 \mathrm{ml} / 24 \mathrm{~h}$ ) and pain management. The surgical intervention was performed right after CT scans evaluation and antibiotic deliviery. Under a general anaesthesia and orotracheal intubation, the two-step procedure was performed. The first step involved a comprehensive dental treatment-extraction of potencial inflammatory foci in oral cavity, and the second one - abscess incision and drainage. Having disinfected the skin in the left temporal area, fresh sterile drapes were put in place and the reported purulent fluid collections were incised and drained. Following a manual revision of abscess cavity recesses, a sample for microbial cultures was taken and drains were sutured in place (Figures 8,9). On subsequent days, the patient's condition improved with decreasing amount of drained contents. On day 3. (72hrs), a negative culture for aerobic bacteria was obtained, followed by a positive culture for anaerobic bacteria on day 6. Gemella Morbillorum was isolated, resistant to metronidazole and susceptible to amoxicillin and clindamycin. Gemella morbillorum is Gram-positive, facultatively anaerobic and non-spore forming coccus. G. morbillorum liveas as a commensal organism of the mucous membranes of the human oropharynx, gastrointerstinal and female genital tracts [21].

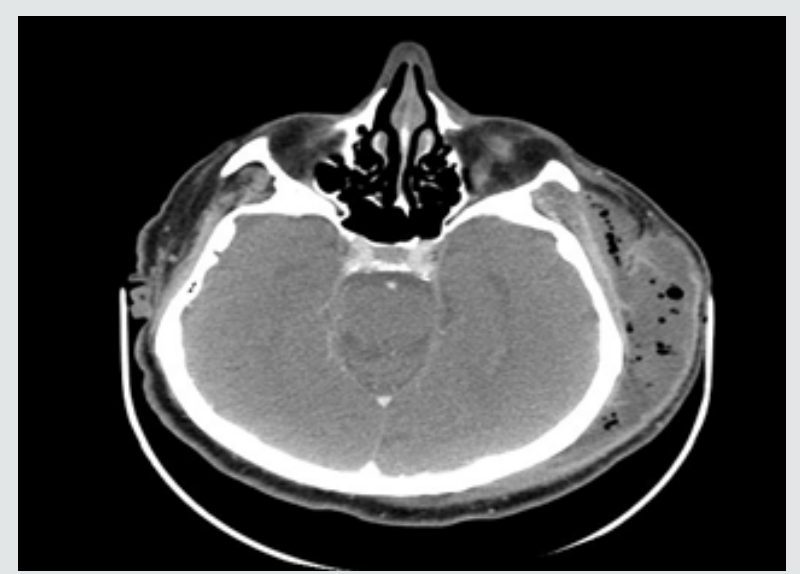

Figure 3: CT image of orbits plane.

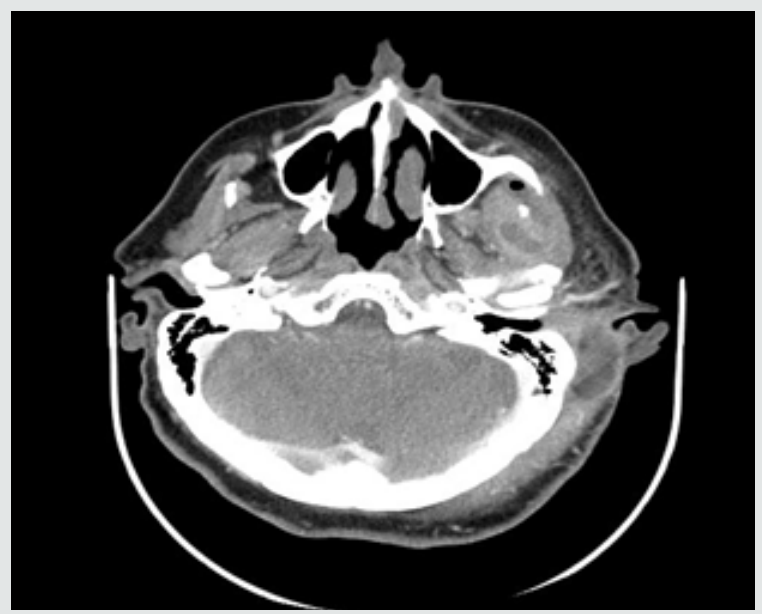

Figure 4: CT image of maxillary sinuses and subtemporal fossa plane.

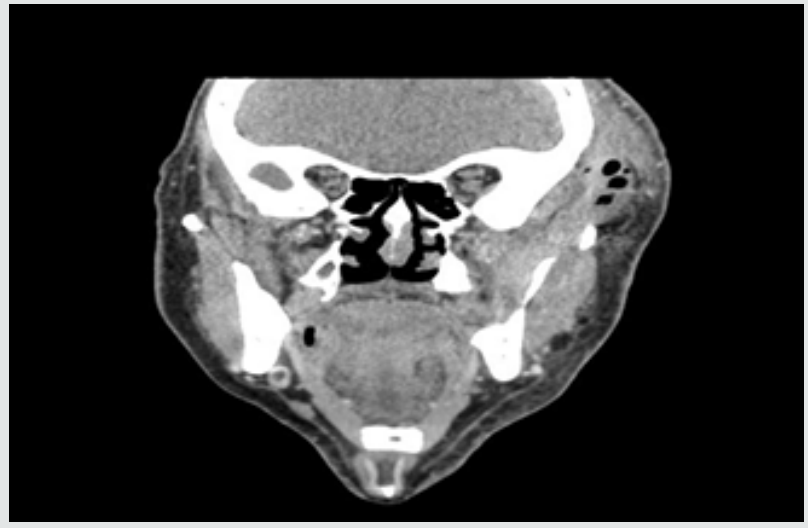

Figure 5: CT image (frontal plane) of the orbital apices. 


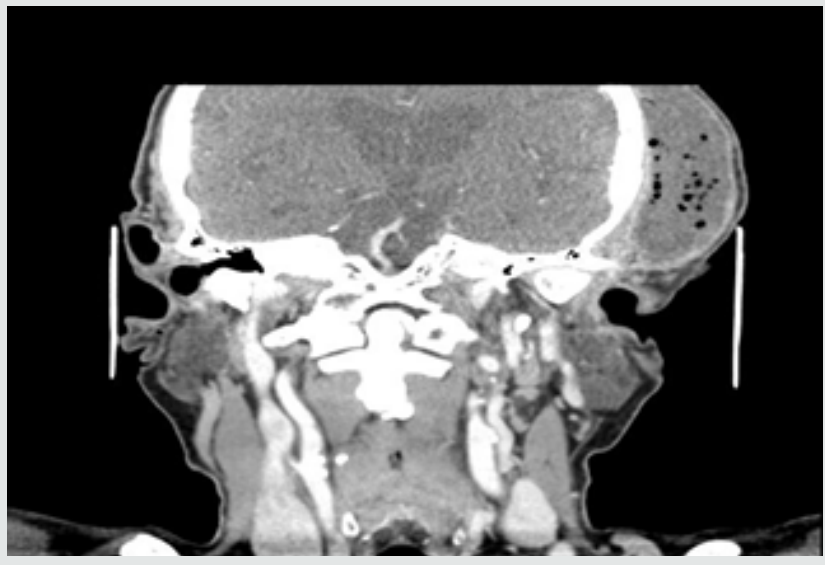

Figure 6: CT image (frontal plane) of the external auditory meatuses.

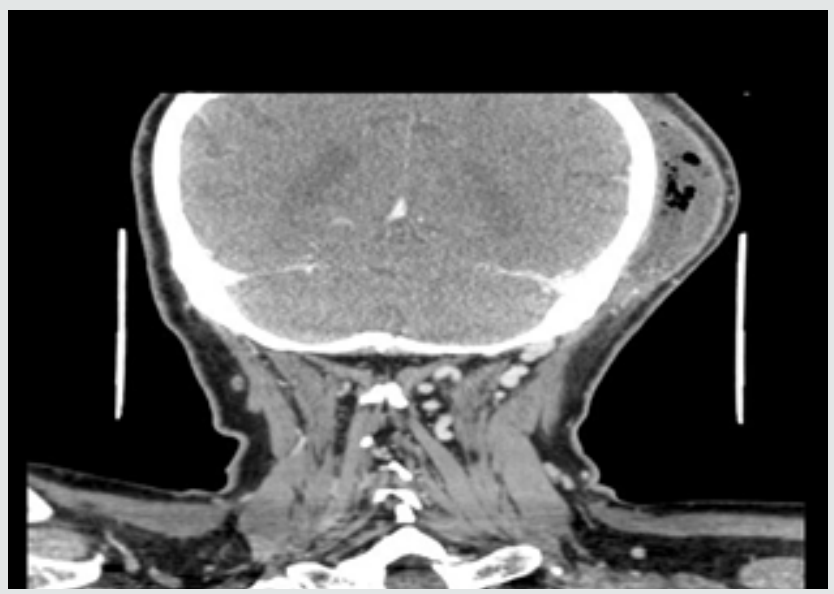

Figure 7: CT image (frontal plane) of the deep cervical muscles.

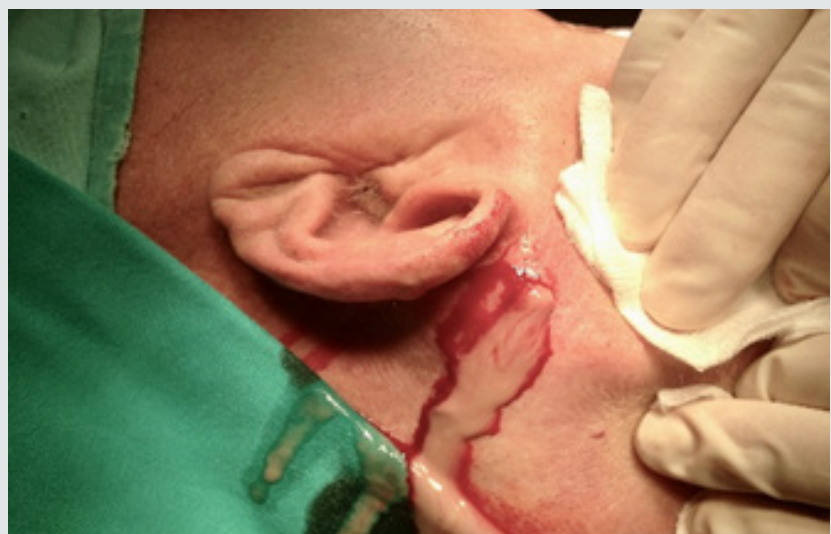

Figure 8: Intraoperative view - an incision in the left temporal area with posing purulent discharge.

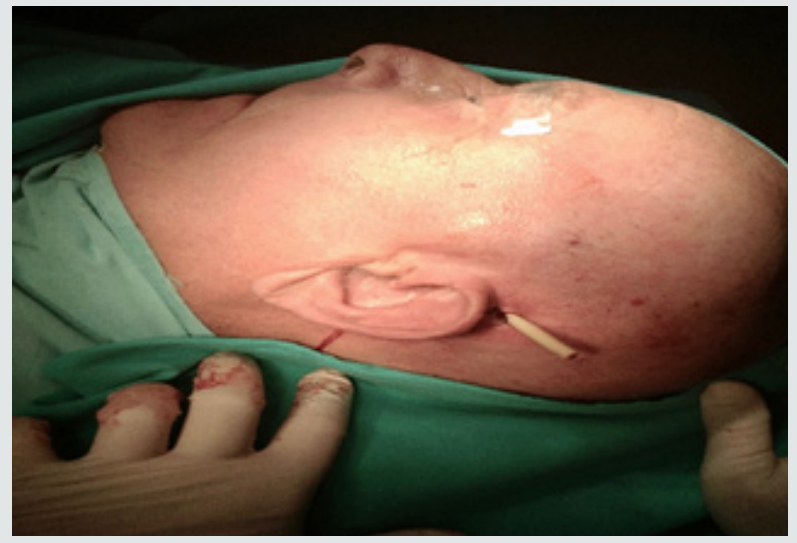

Figure 9: Intraoperative view after the incision and drainage with drains protruding from the abscess cavity.

The antibiotic treatment was adjusted accordingly replacing metronidazole with clindamycin $600 \mathrm{mg}$ every $12 \mathrm{hrs}$ and leaving biocefuroxim dosage unchanged. The decision was guided by susceptibility test findings and the fact that clindamycin itself has fairly low efficacy against Gram-negative aerobic bacteria [17]. The laboratory tests were repeated 5 days later, with a CRP reduction to $13.37 \mathrm{mg} / \mathrm{L}$. One day later, the follow-up contrast-enhanced CT of the head and neck was performed (Figures 10,11). The report stated that "the previously reported extensive inflammatory infiltration and soft tissue abscess within the left craniofacial area was incised and drained, subsequently reducing in size (...). The inflammatory lesions within the temporal and subtemportal fossa as well as within the masticator space have also slightly decreased in size". The patient was hospitalised for 18 days. One day prior to scheduled discharge, the drains were removed and laboratory tests repeated. The findings included CRP reduction to $4.91 \mathrm{mg} / \mathrm{L}$ [reference range $0-5.0 \mathrm{mg} / \mathrm{L}$ ] and almost completely resolved oedema. The patient was discharged home with continued course of antibiotics (clincamycin $600 \mathrm{mg}$ PO twice a day), wound cleaning and dressing change instructions and a follow-up appointment at the Maxillofacial Clinic booked in 7 days.

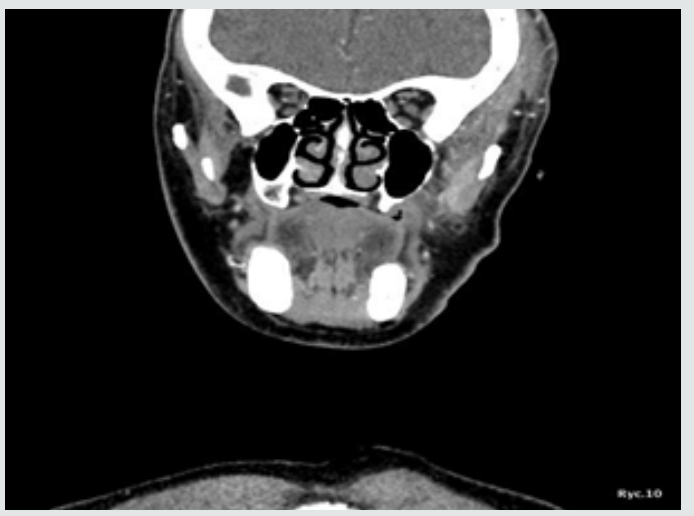

Figure 10: Control CT image (frontal plane) of the orbital apices. 


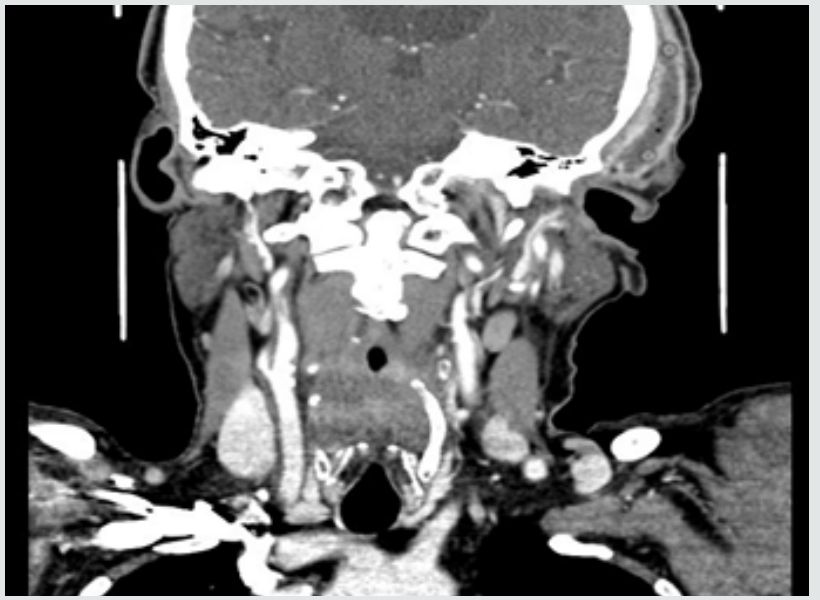

Figure 11: Control CT image (frontal plane) of the external auditory meatuses.

\section{Discussion}

Odontogenic infections still constitute a major group of head and neck infections [2-4]. An infection presenting as local infiltration or abscess may develop secondarily to pathogenic flora presence in necrotic pulp or after any intraoral/ dental procedures involving the alveolar process. The most common procedure is dental extraction, which is always associated with bacteriemia. With local and/or systemic vulnerability and risk factors, dental extraction may lead to a local or-very rarely-systemic infection. The treatment of choice in abscesses is a surgical intervention including incision and drainage, in some cases accompanied by medical treatment $[6,8,11]$. The decision of inpatient admission can be very challenging at times. It should be informed by a thorough history, clinical assessment and diagnostic imaging [12,20]. Any potential life-threatening conditions associated with dyspnoea warrant inpatient admission. Similarly, intraoral abscesses, including canine fossa abscesses, should be treated surgically under general anaesthesia. The infection spread in this case via the route typical of maxillary molars, along the subtemporal space, extending through the temporal space, up to the parietal area [10-13]. Effective treatment of odontogenic infections of the head and neck requires accurate diagnosis. It should be noted that the severity of the general condition may not correspond to the clinical presentation, especially with the involvement of parapharyngeal or pterygomandibular spaces $[9,13,20]$. Contrastenhanced computed tomography is a diagnostic imaging modality of choice in extensive infections of the head and neck, as it enables precise location of the inflammation, especially with the infection spread to the deep fascia of the head and neck. Contrast-enhanced computed tomography helps to differentiate between the nature of the condition (inflammatory infiltration, abscess, phlegmon) and precisely determines its location, identifying the surgical target $[1,16,13]$. The abscess occupying the infratemporal, temporal and parietal fossae may also be occurred by trauma or laryngological causes. However odontogenic infections constitiute over $49 \%$ in head and neck region $[1,14,16]$.

\section{References}

1. Pesis M, Bar Droma E, Ilgiyaev A, Givol N (2019) Deep Neck Infections, Life Threatening Infections of Dental Orgin: Presentation and Management of Selected Cases. IMAJ 12(21): 806-811.

2. Ariji Y, Gotoh M, Kimura Y (2002) Odontogenic infection pathway to the submandibular space: imaging assessment. Int J Oral Maxillofac Surg 31(2): 165-169.

3. Bakir S, Tanriverdi H, Gün R (2013) Deep neck space infections: a retrospective review of 173 cases. Am J Otolaryngol 33(1): 56-63.

4. Boscolo Rizzo P, Stellin M, Muzzi E (2012) Deep neck infections: a study of 365 cases highlighting recommendations for management and treatment. Eur Arch Otorhinolaryngol 269(4): 1241-1249.

5. Goldberg M, Topazian R (2002) Odontogenic infections and deep fascial space infections of dental origin. In: Topazian RG, Goldberg MH, Hupp JR (Eds.), Oral and maxillofacial infections. (4 ${ }^{\text {th }}$ edn.), Philadelphia: Saunders, Philadelphia, pp. 158-187.

6. Moghimi M, Baart JA, Karagozoglu KH (2013) Spread of odontogenic infections: A retrospective analysis and review of the literature. Quintessence Int 44(4): 351-361.

7. Boffano P, Roccia F, Pittoni D (2012) Management of 112 hospitalized patients with spreading odontogenic infections: correlation with DMFT and oral health impact profile 14 indexes. Oral Surg Oral Med Oral Pathol Oral Radiol 113(2): 207-213.

8. Akinbami BO, Akadiri O, Gbujie DC (2010) Spread of odontogenic infections in Port Harcourt, Nigeria. J Oral Maxillofac Surg 68(10): 24722477.

9. Marciani RD (2012) Is there a patology associated with asymptomatic third molars? J Oral Maxillofac Surg 70(9): 15-19.

10. Kinzer S, Pfeiffer J, Becker S (2009) Severe deep neck space infections and mediastinitis of odontogenic origin: clinical relevance and implications for diagnosis and treatment. Acta Oto Laryngol 129(1): 62-70.

11. Piekoszewska Ziętek P, Turska Szybka A, Olczak Kowalczyk D (2019) Infekcje zębopochodne-przegląd piśmiennictwa. Nowa Stomatol 21(2): 120-134.

12. Cordesmeyer R, Kauffmann P, Markus T (2017) Bacterial an histopathological findings in deep head and neck infections: a rectospective analysis. Oral Surg Oral Med Oral Pathol Oral Radiol 124(1): 11-15.

13. Stefanopoulos PK, Kolokotronis AE (2004) The clinical significance of anaerobic bacteria in acute orofacial infection. Oral Surg Oral Med Oral Pathol Oral Radiol Endod 98(4): 398-408.

14. Rega AJ, Aziz SR, Ziccardi WB (2006) Microbiology and antibiotic sensitivities of head and neck space infections of odontogenic origin. J Oral Maxillofac Surg 64(9): 1377-1380.

15. Chandra HJ, Rao BHS, Manzoor APM, Arun AB (2017) Characterization an Antibiotic Sensitivity Profile of Bacteria in Orofacial Abscess of Odontogenic Origin. J Maxillofac Oral Surg 16(4): 445-452.

16. Taub D, Yampolsky A, Diecidue R, Gold L (2017) Controversies in the Management of Oral and Maxillofacial Infections. Oral Maxillofacial Surg Clin N Am 29(4): 465-473.

17. Kaczmarzyk T, Goszcz A, Grodzińska L, Stypułkowska J, Woroń J, et al. (2006) Współczesna farmakoterapia w schorzeniach chirurgicznych jamy ustnej i tkanek okolicznych. Wyd I CMUJ, Kraków.

18. Singh M, Kambalimath DH, Gupta KC (2014) Management of odontogenic space infection with microbiology study. J Maxillo fac Oral Surg 13(2):133-139.

19. Obayashi N, Ariji Y, Goto M, Izumi M (2004) Spread of odontogenic infection originating in the maxillary teeth Computerized tomographic assessment. Oral Surg Oral Med Oral Pathol Oral Radiol Endod 98(2): 223-231. 
20. Sakaguchi M, Sato S, Ishiyama T (1997) Characterization and management of deep neck infections. Int J Oral Maxillofac Surg 26(2): 131-134.
21. Fehrenbach MJ, Herring SW (1997) Spread of Dental Infection. Practical Hygiene P. 13-18.
(C) C) This work is licensed under Creative

To Submit Your Article Click Here:

Submit Article

DOI: $10.32474 /$ LOJPCR.2020.02.000126

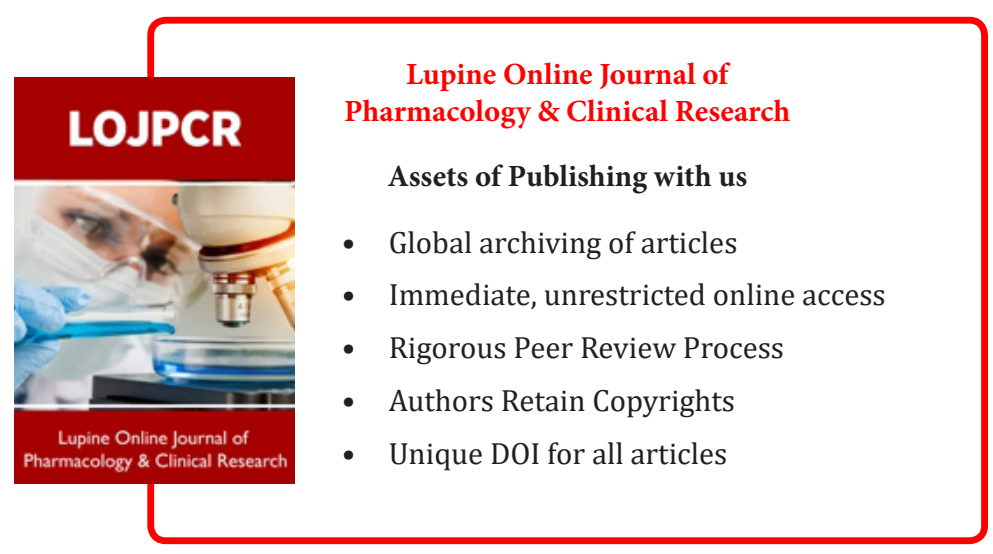

